\title{
How Facebook users select identity categories for self-presentation
}

\section{Gwen Bouvier}

To cite this article: Gwen Bouvier (2012) How Facebook users select identity categories for selfpresentation, Journal of Multicultural Discourses, 7:1, 37-57, DOI: 10.1080/174477143.2011.652781

To link to this article: https://doi.org/10.1080/17447143.2011.652781

曲 Published online: 24 Feb 2012.

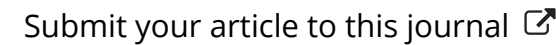

Џlll Article views: 4121

Citing articles: 16 View citing articles 5 


\title{
How Facebook users select identity categories for self-presentation
}

\author{
Gwen Bouvier* \\ Cardiff School of Creative \& Cultural Industries, University of Glamorgan, UK \\ (Received 8 November 2011; final version received 20 December 2011)
}

\begin{abstract}
This paper focuses on the display of identity on Facebook, and more specifically on how undergraduate students in Cardiff, Wales, say they express identity on their profiles. The theoretical context of this study is observed processes of change in the way we play out identity through what have been described as globalisation, deterritorialisation and the rise of lifestyle consumer society. The paper is based on an analysis of responses from a questionnaire and interviews with 100 students from Media and Communication degrees at the University of Glamorgan. The data collection is designed to indicate what kinds of self-categorisation are used. These data are analysed using Social Actor Analysis developed by Machin and Van Leeuwen. The paper shows that we find a range of identity categories, some that are based around a biological model of national identity, while others focus on a belonging to a territory, others on national cultural activities and yet others link to lifestyle identity. What is most notable in this Welsh sample is the high use of nationalist identity categories and biological ethnic classification alongside other lifestyle identities.
\end{abstract}

Keywords: discourse; identity; Facebook; small nations; nationalism

\section{Introduction}

This paper offers a specific contribution to the emerging literature on the display of identity on Facebook. In 2011, the social networking site has more than 800 million active users, of which over 50\% log into their profiles on a daily basis (Facebook 2011). A number of observers have noted that there is need for more research to understand how users present themselves to communicate about themselves in these environments (Livingstone 2008). Such social networking sites have been thought to offer new opportunities for more careful management and presentation of self in social networks and friendship communities. Thus far, much of the literature asks how resources are used to communicate identity, and there has been a tendency to emphasise the way that users are free to create and manage these identities, although this has been examined more at a theoretical rather than empirical level. This has been considered in the way that users may wish to make themselves appeal to specific target communities or kinds of users.

Here I want to think about precisely what categories of identity people use and what they do not use to do this, asking: 'does Facebook foster particular kinds of identity categories as users are involved in participating in social networks and creating community links?' It is a commonly asked empirical question in academic

*Corresponding author. Email: gbouvier@glam.ac.uk 
fields such as Sociolinguistics: 'when called to define identity in any given setting, what kinds of resources are used?' Such a question is not necessarily posed in the same way in Cultural Studies, where much of the emerging research has been produced, and which is generally concerned less with specific linguistic resources and their use. But here I want to show that it is productive to do so in this context.

In any given social context at any given time, there is a range of identity concepts available that should be seen as socially constructed (Foucault 1982). And further, according to Foucault those resources that are in play at any given time often give us a lead on the kinds of power structures in a social context - even if users have a sense these are used by choice and present a positive and liberating classification (Machin and Van Leeuwen 2007). We can then question whether through this, certain kinds of identity are fostered and maintained. In the case of Facebook, while there has been some celebration of the freedom to create identity, it is a useful step to look at the kinds of language resources, the kinds of identity concepts, that are used to do so in a given context.

We might see the context of this study as the observed processes of change in the way we play out identity through what have been described as globalisation (Giddens 1991), deterritorialisation (Negus and Roman-Velazquez 2000) and the rise of lifestyle consumer society (Chaney 1996). Theorists have observed on the one hand that these forces offer newer, powerfully compelling forms of identity, based for the most part around consumer and lifestyle factors that displace the meaningfulness of national identity. On the other hand, others have noted the emergence or resurgence of new kinds of nationalism at symbolic levels celebrated through things like cultural events (Billig 2002).

In Wales in particular, there has been a resurgence in national identity at certain levels, especially since the 1990s through the process of devolution, with the establishment of the National Assembly and financing of the Welsh Language which has lead to a resurgence in some parts of Wales (Jenkins and Williams 2000, xiii). In the second decade of the twenty-firstcentury it appears that there is certainly a resurgence of Welsh nationalism, at least at the symbolic level, where new streets and public buildings will be given names from the Welsh language even if locals have little knowledge of it (Coupland 2010). Yet these new symbolic forms of national and cultural identity, some of which appear to point to a monolithic ethnic Welshness, have been shown to be just as imagined as the nations described by Anderson (1991) in his classic work Imagined Communities and as much constructed and mythologised as described by Gellner (2006) and Hobsbawm (1997). Bohata $(2004,15)$ points to the way that the idea of a nativist Welsh culture is absurd by looking back at a pre-colonial past to salvage what is conceived to be the essential, pure culture that existed prior to the moment of colonialisation (Bohata 2004, 129). Nevertheless, as with nationalism, a particular place becomes fused with 'mythical content and hallowed sentiments' (Williams and Smith 1983, 509). Bhabha notes that the nation can no longer be considered a material reality. It is rather a form of discourse, in which imaginative processes inevitably assume a central role (Bhabha 1994). The same applies to ethnic categories. And what we find in this study is a predominance of this kind of identity being foregrounded on Facebook profiles in this sample.

In the context of Welsh culture, Ashcroft, Griffiths, and Teffin $(2007,79)$ notes that "only a few aspects of traditional culture need be selected as "symbolic elements" around which ethnic identity revolves, and individuals need experience very few of 
the defining criteria [...] to consider themselves members of the group'. They point out a lack of agreement on the nature and specific features of ethnicity amongst members of ethnic groups, underscoring the incompleteness of such a grouping. Nevertheless, this active intertwining of elements of identity has come to function as an increasingly potent arrangement of identity in a world that is progressively more migratory, globalised and hybridised $(2007,79)$. Since Facebook embodies many of these features - the online environment is global and deterritorialised and of course people living in Wales inhabit an advanced capitalist economy where lifestyle identities now flourish - it is of interest to look at the ways that Welsh users classify themselves.

This paper is based on an analysis of responses from a questionnaire and interviews with 100 students from Media and Communication degrees at the University of Glamorgan in South Wales, UK, who had Facebook profiles and who all identified themselves as regular users. These students were questioned as to how they express their identities on their personal profiles, if indeed they do at all. In other words, the data collection is designed to indicate what kinds of self-categorisation are used and how this is accomplished. The research was related to a broader project regarding identity and small nations but the data that was thrown up led to the broader considerations of identity expression that form the analysis in this paper.

These data are analysed using Social Actor Analysis (Van Leeuwen 1996) specifically as developed and applied by Machin and Van Leeuwen (2007). This is a sensitive framework through which features of identity can be monitored and categorised. The paper shows that we find a range of identity categories, some that are based around a biological model of national identity, while others focus on a belonging to a territory, others on national cultural activities and yet others link to lifestyle identity. Some users distanced themselves from Welsh classification. Useful in this approach is Shi-xu's (2005) reminder that discourses are always cultural-politically competing, socially dynamic and diverse. It is out of this process, ultimately, that culturally shared notions of things like national and ethnic identity emerge and change over time. What is 'Welsh' is by no means fixed nor monolithic. Welshness in Shi-xu's terms is a cultural phenomenon and nothing more or less. But nevertheless, discourses, we should not forget, are 'at the heart of personal, social, historical and cultural reality and the construction of action upon reality' $(2005,40)$.

\section{Research on Facebook and identity presentation}

The research carried out for this paper is to be located in the emerging body of literature on social networking sites. Much of this literature has explored the kinds of contacts made on Facebook and pointed broadly to the processes of selfpresentation of identity undertaken by users. A review of this work and the questions it raises shows that it is a useful step to ask, using Social Actor analysis, what categories of self users both highlight and background when constructing their profiles. The precise value of this particular research question will become clearer as the different threads of research into Facebook are reviewed in turn.

Much of the research on Facebook specifically has focused on 'friending', identity performance on personal profiles and within groups, and privacy/security issues (Honeycutt and Cunliffe 2010, 229). It is the first two of these that are of relevance here, since this paper is concerned with the process by which users position 
and present themselves to others to create and maintain connections and to present themselves in a fashion according to those they wish to seek out, or identify.

\section{'Friending'}

Early research on identity and Facebook focused on processes of 'friending'. ${ }^{1}$ It was debated whether initiating new contacts would lead to meeting new people face-to-face (Parks and Floyd 1996) or whether connections were being forged with people outside of users' pre-existing social or geographical circles (Wellman et al. 1996). However, as social networking sites like Facebook have become mainstream media, research has shown that this has not been the case. Lampe, Ellison, and Steinfield $(2006,169)$ found that social networking sites are used in the first place as a tool to maintain established connections (see also Chiung-Wen, Ching-Chan, and Yi-Ting 2011).

There has been more concrete research that has attempted to log the exact nature of the kinds of connections created through social networking sites, which have been argued to consist of jumbled, mixed collections of contacts, ranging from old school-friends, relatives, close friends and other people they met randomly (Lewis and West 2009, 1209). But subsequently the question has been asked whether there is a need to find out more about the function and nature of the different kinds of contacts in users' long lists of 'friends' (Tong et al. 2008; Davis et al. 2011). One area that has only just begun to be explored, as in the work of Livingstone (2008), is the way that users actually position themselves to engage with particular communities or kinds of other users. The importance of this matter can be clarified by a look at the other main thread of work on Facebook, that of 'identity'.

\section{Identity performance on personal profiles}

Theorists working on identity performance on social networking sites have tended to draw on the work of Goffman (1959). As in everyday life, there is a process of self-presentation on social networking sites, where we perform who we are, managing this in various ways at different times and contexts. But the difference between the two, as perceived by most commentators, is that on social network pages this has been more reflexive as users have much more time to carefully craft their displayed identity (Champagne 2008, 164).

The attention of some authors has been drawn to the way that displayed identity on Facebook may have only limited correspondence to that in the 'real' world (Sunden 2003, 109). Indeed, while creating fake profiles has been outlawed on Facebook, hijacked identities (posing as Hollywood stars, for example) or wholly fictitious personas do exist on the site (Westlake 2008, 29). As such, debate has been ongoing about whether Facebook profiles are used to create and communicate idealised versions of selves, or whether social networking sites serve as an extension of our social context in which one's actual personality characteristics can be expressed (Vazire and Gosling 2004; Ambady and Skowronski 2008; Manago et al. 2008; Back et al. 2010). Other writers suggest that with the routine everyday use of these technologies, the simple distinction between offline and online no longer captures the complex interrelationship that characterises use and the way media like Facebook are embedded into lives, particularly amongst young people (Livingstone 2008). 
Others have focused on the interactive nature of self-presentation on social networking sites. Boyd and Heer (2006) suggest that users are key in shaping the presentations of others as they provide their own comments and Wall postings. User presentations take into account the diversity of an audience consisting of familiar and not-so-familiar social relationships (DiMicco and Millen 2007). The Facebook community can be conceptualised as a team performance, achieving Goffman's (1959, 83) 'dramaturgical cooperation' in confirming each other's performances of self (Westlake 2008, 27).

Some authors have pointed to the way that identity is performed on personal pages through a combination of text, image and sound (Lampe, Ellison, and Steinfield 2007, 1). Such crafted representations are 'purposeful and outer-directed' and 'self-production is heavily narrated', pointing to the connection between user profiles and the mainstream culture industry (Hearn 2008, 197). Many users will provide access to their daily 'diaries', complete with photographs that may or of course may not be heavily selective. Zhao, Grasmuck, and Martin (2008) found that users do not necessarily create personal artefacts but prefer to display material (quotes and images, for example) that are in the public domain. As such, these users 'predominantly claim their identities implicitly rather than explicitly; they "show rather than tell" and stress group and consumer identities over personally narrated ones.' (2008, 1816).

What as yet remains to be more fully explored and documented are some of the more precise ways that users do present themselves for specific groups of others. In this context Livingstone $(2008,396)$ appears to be taking the lead by asking the right level of empirical question - how do users present themselves to approach the right networks? In this paper I look at how users speak about the way they present identity, through a range of semiotic resources, specifically with an interest in the kinds of categories of identity they use. One of the central concerns of discourse studies is the way that discourses, values, ideas and identities are disseminated, maintained and legitimised in society. If here we take the idea of team performance of identity, rather than an identifiable elite media source as is commonly the site of analysis in discourse studies, we can nevertheless monitor what kinds of identities and therefore values, ideas and broader discourses are present on Facebook.

\section{Changing concepts in identity research and 'regimes of identity'}

This paper also draws on, and sees relevant, key issues in current identity theory in Sociology and Linguistics. Particularly relevant are discussions of the constructed nature of identity and the changing 'regimes' of identity under which we live (Machin and Van Leeuwen 2008). Under each of these regimes different resources are available for defining the self and these always reflect the interests of those in power at each time (Machin and Van Leeuwen 2007). It is this assumption and the classificatory framework offered by Machin and Van Leeuwen that forms the theoretical and methodological basis of this paper. This section sets out the developing theory on identity to locate this research, then moving into the methodological framework.

The first of the regimes of identity is that of the nation state. Here identity is about us belonging to a nation state which is constructed as timeless and more or less populated by a monolithic people (Gellner 2006). Anderson (1991) looked at the role of the rise of the printing press in the ability of a nation state to create a 
sense of shared membership of an imagined community of others that we will never meet, and many of whom we will have very little in common with. Gellner (2006) shows how these nation states are in fact, despite their self-presentation as timeless, fairly recent social constructions. Machin and Van Leeuwen (2008) have analysed the kinds of categories of identity fostered by the nation state as part of their interest in controlling and mobilising populations. In the ideology of the nation state people are not to think about themselves in terms of social class, occupation, family connections or relative poverty, but by provenance, in terms of where you are from. Abousnnouga and Machin (2008) have shown the deliberate fostering of the Welsh identity that took place after First World War, which was a reaction to fear of the left wing politics of the working classes in South Wales at that time. The work of some of the key thinkers in Sociology, such as Simmel (1917), Tönnies (2001) and Durkheim (1897), was highly concerned about the shift from identities based in those of small rural communities to those based on the anonymous large-scale society that insisted on the category of the more abstracted national identity.

The second regime of identity is that of lifestyle. Identity expressed through lifestyle can rest on the use of signs that are loaded with cultural meaning. Zablocki and Kanter $(1976,270)$ noted that lifestyle is a major element of identity formulation for those 'for whom identity has come to be generated in the consumption rather than in the production realm'. Though it can rightly be said that people use consumption and consumer goods to express their selves, such markers of lifestyle also use them, as consumers are tracked and monitored through marketing surveys and the large corporations and social institutions whose interests this serves. (Machin and Van Leeuwen 2008, 54)

Identity as a cluster of life(style) choices, then, also provides a person with rules, roles and relationship criteria for living (Walters 1994, 98). Lifestyle thus determines a range of choices and aims in someone's life, as a 'more or less integrated set of practices which an individual embraces [...] because they give material form to a particular narrative of self-identity' (Giddens 1991, 81). Further, the concept of lifestyle does not relate to a resistant relationship to other - more essentialist factors of identity or to a dominant culture, but rather emphasises distinctions in practice with class culture (Chaney 1996, 35). Whereas other regimes of identity are constrained by socially constructed or 'imposed' models of identity (such as the other regimes described here) and by the institutions that maintain them, the arguably more advantageous lifestyle identity has the drawback of being dependent on people's financial resources (Machin and Van Leeuwen 2008, 55). These authors note that in the twenty-first century it is lifestyle identity that has come to the fore as this reflects the interests of large corporations who seek to safely fuse ideas, attitudes and values to consumer patterns.

The third regime of identity is that of cultural or ethnic identity. We can say that cultural identity and ethnicity can be equally as imagined as those reliant on nation. Categories of identity based around ethnic features are often linked into cultural heritage. In Postcolonial studies it has been shown that much of these classifications too are constructed, as is national identity. Stuart Hall (1989) has mentioned the way African identity is often spoken of as if it is something tangible and timeless. He critically points out that the idea of 'Caribbean identity', like 'African identity', can hide differences within, and obscure how people change. It is this model of identity - which essentialises who we are to a single feature - that leads 
to phenomena such as the tendency to have one black or Asian representative on a committee. Just as if there was something essential about all blacks and Asians that means they could be represented by a single person (Machin and Van Leeuwen 2007).

A further important body of literature upon which this paper draws is that around the nature of identity itself, of how individuals source, construct and negotiate identity. Self-identity is understood here as an individual's perception of who he or she is, linked to self-assessment and, arguably, continuous re-evaluation. The concept presumes continuity through time and space (Giddens 1991, 53). So, importantly, it is not a distinctive trait but can be considered a response only to a prompt to self-define. Bhabha (1994) emphasises the way that in any society at any time there are a range of identity categories available to people which they can bring to the fore when necessary, and which can vanish from view for the same reasons depending on what is to be gained or what is perceived to be appropriate or possible. For example, a working-class miner from a town in the Welsh valleys may consider himself a man, a miner, white, Welsh, a football supporter and a father. Are these identity categories in his mind, or are they simply appearing to him as facts about his life? This indeed ties in to Giddens' $(1991,53)$ notion of self-identity, which stems from the work of Simmel (1917) and Durkheim (1897): ' $[\mathrm{It}]$ is not a distinctive trait, or even a collection of traits, possessed by the individual. It is the self as reflexively understood by the person in terms of her or his biography'. So Giddens reflects here on the cognitive component of our identities.

There are some categories of self that are, in our society, still assumed to be 'defining' who one really is. While national identity and provenance may say nothing about what someone is like, it still has the currency of self-definition.

Others, such as Bhabha (1994) have pointed out the way that these categories can become practical tools that individuals can use in contexts. There might be many categories that they can draw upon: black, male, footballer, music fan, lad, mate, hot lover, guy who knows about cars, as well as regional and national affiliations. In different situations any one of these can be brought to the fore.

The introduction of this paper mentioned changes in society. Chaney (1996, 2001, 2002) has referred to this new society as a lifestyle society where we more or less self-consciously engineer categories of self that may be more or less permanent. Yet now we might argue that who we are is defined by broader patterns of consumption. And certainly we are addressed, and to some extent socially organised on this basis by corporations. A range of scholars have pointed to this phenomenon (Giddens 1991; Chaney 1996). We might say someone is Welsh only in a moment where called to 'define the true self', whereas in the rest of our lives we know ourselves according to our lifestyle choices. As yet, these lifestyle categories have not yet become established as acceptable definers of who we really are. Who we 'are' may mean that we are more like a person who lives a thousand miles away, but who watches the same television, wears the same clothes, drives the same car, eats at the same sushi restaurant, etc. But this is not yet who we can say we are (Machin and Van Leeuwen 2007).

Giddens (1991) also suggests that never before have there been so many situations, with contemporary media and mobility, where we are called upon to have identity. Bhabha (1994) warns that nevertheless some aspects of identity are taken up as 'what we are' in ways that can be less easy to background. An example of this is categorisation based on provenance on Diversity Monitoring Forms 
(Machin and Van Leeuwen 2008). A given person can never cease to be British Asian. Even if they were born in Britain and never ever been abroad, they are always one step away from simply being 'British' on such classification systems. However much this person is like their white friends, 'race' and regional association (Asia) is something they cannot escape. So we can also ask how much classifications can imprison us and maintain barriers between people that have long ceased to be meaningful in the globalised world.

There is also a debate around the extent to which there is therefore no essential identity but rather one that is in flux. Indeed, this ongoing discussion suggests a 'crisis of identity' is taking place, as the concept has undergone significant shifts in its theorising, with for example Gergen (1991) and Featherstone (1992, 1995) suggesting that the 'core of the self' has lost its significance. This allows us to think of identity as something that is unstable, changing and constantly fluctuating. This contradicts the way identity was thought about before the globalisation debates became so widespread.

Others argue, in contrast, that we must not lose sight of the fact that it is institutions such as the nation state and global corporations that often supply us with these categories of identifying ourselves. And while we may to some extent control them, they also control us (Machin and Van Leeuwen 2008). Identity categories are not given in nature but created in language, and we cannot describe ourselves outside of the categories available in any society at a given time. Powerful institutions will seek to naturalise those that support their own interests. Possibly, the flux model loses sight of this. Whose interest, we must always ask, do these identity categories serve?

It is this discussion of identity, its changing nature in the context of the lifestyle society, where in the case of Wales there is a new surge in nationalism, but where nevertheless we appear to find ourselves in increasing situations where we are called to identify who we are, and in an increasingly globalised and decontextualised setting. It is into this context that we must understand Facebook and into which we must place the kinds of questions posed earlier of the way people manage identity and engage with different communities through their profiles.

\section{Methodology: discourse analysis and Van Leeuwen's classification of identity construction}

One key area of interest in discourse studies has been the resources available to and used in any social group for speaking about people as individuals and groups. These resources are not simply seen from this perspective as descriptive, but as ideologically loaded and serving specific interests. Language is viewed not as simply a way through which we describe the world, but one by which we can creatively form accounts of the world that reflect our own interests (Kress 1982). Above we have already considered the way that the nation state promoted national identities over other kinds of social allegiances to promote their proper interests, and for example to distract from matters to do with issues such as poverty, an issue that crosses national boundaries. A number of writers in discourse studies have stressed the usefulness of analysing the representational strategies used by authors of texts such as newspaper articles and political speeches. For example, if we find that a journalist in a crime report uses lexical choices that draw particular attention to the young age of a group of men accused of anti-social behaviour (Teo 2001; Mayr and Machin 2012). In this case we 
could argue that the author, rather than explaining the behaviour in terms of poverty and unemployment, chooses to signify a discourse where youth is out of control in society.

In this paper I draw specifically on the set of tools for assessing representational strategies offered by Van Leeuwen (1996) in his paper on social actor analysis as developed and applied by Machin and Van Leeuwen (2008). These prove highly productive in the analysis of the identity categories used by the surveyed students to express their identities on Facebook. I first describe these and then make comments on the nature of the questionnaire.

Looking at the linguistic resources for expressing identity, Van Leeuwen (1996) argues that there are two types of categorisation for describing self when we are prompted to. These are 'functionalisation', meaning people are described in terms of what they do (e.g. a fire-fighter) and 'identification', meaning people are described in terms of what they are. Three different kinds of identification are set out: 'classification', 'relational identification' and 'physical identification'. These differentiate on the basis of the ideology that is at work in the type of identity description.

In the case of 'classification', a person's identity is defined 'in terms of the major categories by means of which a given society or institution differentiates between classes of people' $(1996,54)$. These can be things like being 'French' or being an 'immigrant' or 'homosexual'. However, these categories can change over time and across cultures. What in one period or culture may be considered a practice (something you do), can become a more fixed feature of your identity in time or place. For example, the practice of sodomy eventually became an identity, a homosexual (Machin and Van Leeuwen 2008). Machin and Van Leeuwen (2008) note that such changes occur slowly, and start off as being new ideas, to then be turned into practices, and finally end up as a way of being. Importantly, they always are linked to the interests of the institutions that introduce and promote them. Therefore, it is important to ask whose interests these terms of classification serve, and how they do this (2008, 46). In Britain being classified as 'British', or 'British Asian', may represent little about the actual person themselves, yet this kind of provenance is still a taken for granted marker of identity. When we meet a person they will want to know where we are from, even though this will tell them very little about who they are, even if they only lived in this place for a few months of their lives. A colleague of mine often speaks of her Welsh identity and character. Yet when I saw her in a poor area of Wales she appeared to have little sense of commonality with the tattooed, lager swilling unemployed locals on the sea front to whom she showed contempt and disgust. In later conversations she forgot about this difference; such is the compelling nature of the established categories of identity in a given society at a given time. Classification in terms of national identity, where there is a monolithic people with a long cultural heritage, is particularly important in Wales currently. This was discussed above, as since devolution occurred, it is the task of a range of committees and organisations to promote 'Welshness' and Welsh cultural identity.

'Relational identification' defines people in terms of their connections, for example to family, friends, or colleagues at work. Machin and Van Leeuwen (2008) note that relational identification plays an increasingly marginal role in Western society, but anthropologists have shown that in many societies it is the single most important form of 'classification'. Von Sturmer (1981), for instance, has described 
how Australian Aborigines, when they first meet, 'search for relations whom they share and then establish relationships on that basis' (1981, 13). More locally, in former times people might have been called to define themselves in terms of who their father, their aunts and uncles were. Family connections in Britain have however ceased to be a currency by which someone's status and identity is understood.

'Physical identification' aims to describe identity as constructed in terms of physical characteristics. This can be expressed across a limited range of physical characteristics such as hair or skin colour, clustering particular groups of people (e.g. 'blacks', 'blondes'). This type of identification is also present where people speak of groups of people in terms of things like national character that are seen to be something akin to being genetic. A friend of mine in Wales often refers to the behaviour of the national sports teams as being indicative of national character. I found this interesting given that many of the players would be only distantly connected by family and had never lived within Wales itself. This kind of identification has in extreme form lead to horrific racist policies (e.g. nationalism in 1940s Germany).

In the case of 'functionalisation', Machin and Van Leeuwen (2008) demonstrate that this is the categorisation favoured by societies dominated by lifestyle and consumerism. Marketing companies originally developed and used the 'lifestyle identity' model. Classifications of consumer identities define us in terms of clusters of features which are more changeable than those forms of identity pitched by nation states, ones rooted in the idea of a monolithic people with a common cultural heritage. In 'functionalisation' people are grouped on the basis of what they think, what their political outlook is, to what extent they are independent in spending their incomes, as well as what hobbies they pursue and what media they choose to consume (e.g. what magazine titles they read). In addition to these features, the lifestyle model also looks at consumer behaviour and takes into account a number of more traditional demographic categories, including race, nationality, place of residence and age. 'Lifestyle' identities of this kind emerged as corporations looked for new ways of creating market demand. We can see that while the colleague who often refers to herself as Welsh uses an idea of classification based on what she is in such conversations, when confronted with poorer people which the nation state would also want to classify as Welsh, it appears to be 'functionalisation' that dominates her thoughts and actions - in other words its not what you fundamentally are that is important but what you do and how you behave. The same woman lives to spend time on London where she speaks with excitement about how people like culture, theatre and good dining. She has been heard to say she feels at home there. In this case functionalisation is the identity classification to which she aligns.

Where the nation state classifies people as what they are in terms of 'black', 'Muslim' 'Welsh', we can see that this glosses over the huge diversity of life experienced by these people. Some will be poor, some wealthy, some single parents, some long term unemployed. Many of these people have more in common with those of other monolithic groups. Some argue that the use of such groups while promoting rights and equality in fact serves to conceal the structural inequalities such as poor health, education and opportunities for work that cut across the lower socio- economic sections of such groups (Singh 2001). If 'functionalisation' had been the dominant mode of categorising people, it might have been easier to see that 
people from all these racial, 'ethnic' and national categories do the same kind of things, even if they 'are' not the same. They go to school, set up households, purchase goods and services, work, pay taxes, and so on (Machin and Van Leeuwen 2008). But this is not the case.

What I ask in the analysis of the data that follows is what kind of identity categories the sample of Welsh students in this study identify when they are asked how they present themselves on Facebook. Which categories do they foreground and which do they background?

The questionnaire used was open ended and contained the simple questions 'How do you present yourself on your Facebook profile?'; 'What kind of identity do you present?'; and 'Explain how you communicate this'. Students were randomly approached over three lunchtimes in the lobby of Glamorgan University. They were asked if they were Welsh and if they had a Facebook profile. This was done until 100 had been selected and had agreed to complete the questionnaire. The researcher then contacted the students via email upon receipt of the questionnaire where they were asked to participate in interviews to expand on the information provided. Forty two students provided further interview material. The quotes that are cited below come entirely from the questionnaires.

\section{Data analysis}

In the existing academic research into performance of identity on Facebook I found what we can characterise as seven key questions being asked by researchers. We can look at the kinds of categories used to reflect upon these:

(1) Is there a difference between the ways in which people perform identity in everyday life and online on social networking sites? Is performance more reflexive on the latter since users have more time to craft what is displayed (Champagne 2008, 164)?

(2) Are profiles used to create and communicate idealised versions of selves or do social networking sites simply serve as an extension of our social context in which one's actual personality characteristics can be expressed (Back et al. 2010)?

(3) Do user presentations take into account the diversity of an audience consisting of familiar and not-so-familiar social relationships (DiMicco and Millen 2007)?

(4) Can the the 'Facebook community' be conceptualised as a team performance (Westlake 2008, 27)?

(5) Do users mainly claim identities implicitly rather than explicitly?

(6) Do they stress group and consumer identities over personally narrated ones (Zhao, Grasmuck, and Martin 2008)?

In what follows I give examples from the responses on the questionnaire under each of the classifications used by Machin and Van Leeuwen (2007) as these provide one very useful way we can assess the kinds of identity categories used by the users. What we find is that users draw on different classifications in combination and in contradiction. Examples are given from each category with a view to developing responses to the questions posed above. 


\section{(1) Classification}

In the case of 'classification', a person's identity is defined in the terms of the major categories by means of which a given society or institution differentiates between classes of people. In the following we see how respondents often identified themselves by drawing on national classifications. Here, markers of national identity were important. Respondents (45\%) mentioned national identity.

I like to articulate subjects of a patriotic nature, mainly rugby which is a Welsh passion!

I like to show picture of the place where I live: the Valleys which shows Welsh history. I am proud of my Welsh heritage and want to share this.

I have information that says I'm from Wales.

My nationality is an important part of who I am and I like to have this clear on my profile through pictures of countryside and flags.

Use photographs of landscape, the words from the national anthem and rugby to show what I have in common with other people, to show what I want to share.

I don't speak Welsh but I have words and places in the Welsh language there to show what kind of person I am and where I belong.

sometimes I put in Welsh words.

I like to link to Welsh bands and other Welsh Culture. I want to show I am proud of who I am.

I am a member of the Welsh Facebook group.

National belonging is underscored in these answers. Given how national identity actually plays a part in the everyday lives of these students it is perhaps an indication of the current politics of Wales, or perhaps particularly Cardiff where this study took place and which was the location of the Welsh government. In the virtual and borderless sphere that is Facebook nearly half of the students mentioned nationality.

\section{(2) Relational identification}

Relational identification defines people in terms of their connections. What we find here is that users draw on a range of familial, sport, friendship and linguistic relations. Users $(63 \%)$ said that it was important in terms of how they were seen to have these kinds of indicators. Sport was high at $44 \%$, and mentions of a relation to Welsh language speakers came in at $8 \%$.

All my family are in photos on my user space.

I like it to be known that I am a member of the Cardiff City fan club and that I meet regularly.

Mainly music cool music. I want to make friends with new people who know good Indie music. You can see from my site what kind of people we are. 
You can see that I am at the University I guess and a student. Lots of chat is about this and I always have new pictures of nights out I like to be seen as a busy fun person.

'I am into motorbikes and racing'. I have this on my profile and you can see the pro groups if you know the scene.

I like to belong to Welsh language communities, I am learning.

I use Welsh language especially to speak about Rugby. But I want to show I don’t like Welsh learners as these irritate me.

Others say they use language to signpost friendship alliances and involvement with local youth culture:

Saying expressions me and my mates use a lot.

Typical Valleys - saying 'like' and using phrases people from my town use eg 'tidy'.

Relational identification was also accomplished through provenance. For example:

I have pictures of my ancestors who are in places that are still there.

Earlier in the paper it was noted that in a former era in the UK people would have defined themselves in the first place in terms of who they knew. Anthropologists have shown how in many societies things like locality, where you were born, or your job are considered irrelevant as evidence of identity. Who you are is understood through the people you are connected to. Here we do find relational identity, but mainly tied to locality and lifestyle groups such as popular music, sports activities and other popular culture, forms of identity that are very much in constant flux and could be argued as typical reflexive flowing identity markers of postmodern global culture.

\section{(3) Physical identification}

'Physical identification' aims to describe identity as constructed in terms of physical characteristics. While national identity was important throughout, it was also expressed through physical terms with $12 \%$ mentioning this. Four percentage mentioned issues of beauty.

I am interested in modelling. I want to be associated with glamour. I have some professional pictures on my site.

My main hobby is bodybuilding. Loads of my pictures show competitions and famous bodybuilders.

I always choose pictures where I look really ugly. I want to laugh at the idea of mush [sic] of the posing that goes on.

The greatest reference to physical identification was through the following types of references: 
I want show in my profile that I was born here and 100\% Welsh.

I see myself as Welsh though I was born in England but my nan is Welsh. I wanted to explain this on my profile. I can show that I belong to both sides.

I'm not Welsh born but have lived here all my life and its important to me to be show everyone I am Welsh.

I want to show I am born and raised in Wales. This means we straight away have a belonging together.

I wasn't born here but consider myself Welsh. I've lived here a long time and my parents live in Anglesey. I have pictures of the Valleys and of Anglesey.

I was born and bred in the valleys and that makes a kind of person. I like people from the valleys and show it.

Some users also explained that physical identification can be defined through more specific biological definitions in terms of how much they were genetically Welsh. Some pointed to Facebook quizzes that present a set of questions which gauge one's knowledge about Wales and cultural information. Only a very small percentage $(3 \%)$ of respondents brought this to the fore as an important marker of their Welsh identity, but it was nevertheless present. Consider for example:

I'm only half welsh and that's the best bit is on my profile.

having $100 \%$ Welsh as my profile pic!

I have on my page 'How welsh are you' I'm $78 \%$ so its proudly on my profile.

One respondent who added a comment that their site carried links to Welsh nationalist groups explained that:

It worries me that too many people come in over the bridge. In the end we won't know what is welsh and what isn't.

Such forms of identity classification, and the extent to which they were found, were a surprise to this researcher. This kind of system of classification where we are concerned with matters of biological purity of course has a particular kind of tragic and terrifying history of its own (e.g. Nazism). On the one hand this sense of ethnic purity is something that can often be seen on t-shirts sold in market places, and can be seen as simply a form of humour. Then again, just because something passes as humour this does not mean that it does no ideological work. I grew up in Belgium and spent some time in The Netherlands, where there was a tradition of telling jokes about the Belgians. Some were indeed amusing, but all of them felt somewhat smug and cruel when you are often the subject of them. What is also important in this kind of identity classification is that it claims to be fixed. Unlike the relational identification with popular culture groups, biology is not reflexive and not in flux. And, as is indicated by the last comment, it is fundamentally exclusive. 


\section{(4) Functionalisation}

This, according to Machin and Van Leeuwen (2007) is where people are classified in terms of what they do, what they think, what their political outlook is, as well as what hobbies they pursue and what media they choose to consume. Along with provenance - i.e. where are you from originally? - this is in limited form high on the list of identity markers used by the students. Fifty-eight percentage mentioned these kinds of identity categories. Of course we can see that these can also fall into the relational category where users want to suggest that they are like a category of person.

I talk about loving my Rugby.

I am a skater. I like to talk and meet with other skaters in the Valleys. I like these people.

Most of my friends are now people who surf. These are people who know how to live. On my user profile you see how important that is in my life.

I am a huge Dr Who fan. My profile pic shows me next to a Cyberman.

All my Facebook friends are now into the DJ music scene. Most are from London where you have to be.

None of the users said that they described themselves specifically as a kind of student, and none did so through employment categories, although this might be different of course with non-students.

On my profile it is pretty clear I am a Bluebirds (Cardiff City Football Club) obsessive

I'm afraid to say. Only another fan would understand what this means.

This was the highest recorded identity classification, as might be expected if we are to accept the comments by the likes of Giddens (1991) and Chaney (1996), who noted that identity is becoming more reflexive and based around what we do, rather than what we are. This marks a shifting away from former categories based around class, the latter having completely disappeared from the categories used by students in this study. A Dr Who fan is not so much what you are but what you do at certain times, and may be something you will later become bored with and move on to do something else.

\section{Discussion}

I now want to first make some comments about the kinds of identity categories used by the students, and then return to address the core points from the literature on Facebook and identity.

What kind of freedom do we see here, since Facebook has been celebrated as a site of liberation as regards the expression of identity? What we find is that identity for the most part is still highly reliant on older classifications surrounding the nation state, which is astonishing in this time characterised by some in terms of the blurring of national boundaries. The most surprising feature was that we find a lot of physical identification. There has been discussion (see Giddens 1991) that 
individuals, in the context of the ambiguities and blurring of boundaries in the contemporary word, will tend to re-engage with such ideas, although the matter of racial purity is a disturbing one. But given the extent of the new promotion of Welshness in the context of devolution in Britain, and the arrival of the Welsh Assembly, this should perhaps be expected. Although in ideological terms, we might ask who this will ultimately serve.

We also find relational identification but this was never considered important in terms of family but rather again in terms of locality or in terms of consumer and lifestyle groups, which were also important in terms of functionalisation. And importantly, relational identification never involved co-workers, social class, or any sense of political or social identification, apart from one of simple belonging. Nor is it expressed what kinds of values or aims are shared by these relational communities, apart from the fact that they like a particular kind of popular culture.

What is notable is that all of these categories are temporary and easily sit alongside those that are contradictory. Even the nationalist comments are about lifestyle. Bhabha's (1994) sense of people being able to bring identity features to the fore when necessary appears to be better now characterised as people floating over their chosen resources in a less than committed way. Identity itself has becomes a pastime. Even collective identity and community appear to become a matter of individualism - of course in this sense they very much fit with the individualism required by consumer capitalism.

As mentioned, there is ongoing debate about whether the 'core of the self' has lost its significance. This allows us to think about identity as something that is unstable, changing and constantly fluctuating. But we must not lose sight of who supplies us with the categories that we use. Identity categories are not given in nature but created in language, and we cannot describe ourselves outside of the categories available in any society at a given time. All of the uses of identity we find in this paper suit the purposes of those who would seek a population that is not mobilised into communities that have some kind of social action and responsibility at their heart but one that is focused around acts of consumption.

We can develop this discussion into more concrete points if we now return to the six questions above as regards Facebook and identity with a view to what the data presented in this paper contributes.

(1) Is identity performance different from everyday situations with the online version being more reflexive, since there is more time to do so? This appears to be the case, for example where images are deliberately chosen. For example, those that show a person with a Welsh flag; a t-shirt that says '50\% Welsh and this is the best half'; sat alongside a $\mathrm{Dr}$ Who character; or surfing. They can also select which groups (for others to see) they are aligned with. $24 \%$ said that they did like to choose groups for this purpose.

(2) Are profiles used to create and communicate idealised versions of selves, or do social networking sites serve as an extension of our social context in which one's actual personality characteristics can be expressed? The evidence appears to support the former. While users may in their everyday lives have little to do with nationalist activities, as a student, as they sit in a café, chat with friends and family, and watch TV at home, they can nevertheless present themselves through extreme nationalist discourses as champions 
of a community. They can show themselves to others as being at the heart of a football supporting community. All these communities can be presented as entirely homogenous and monolithic in each case.

(3) Do user presentations take into account the diversity of an audience consisting of familiar and not-so-familiar social relationships (DiMicco and Millen 2007)? The evidence from this study suggests this is not the case. Users may have a number of identity categories such as nationalism and sport. But they imagine these as familiar and known. For example, the assumption that people who are in favour of national identity will also be concerned with genetics. In one sense, this is not unlike the kind of imagined community described by Anderson (1991). Whatever the community, it is assumed to be known and have shared experiences. While these communities may be idealised, users assume them to be known. Nor do users appear to speculate where such communities overlap. Are all their fellow Dr Who group members also nationalistic like themselves? As users engage in communities, since other categories of identity are backgrounded, such overlaps are sidelined. In this sense there is a lack of reflexivity, even if there is a level of what Bhabha (1994) would see as shifting in what categories are emphasised at different times.

(4) And we can ask the extent to which the 'Facebook community' can be conceptualised as a team performance (Westlake 2008, 27). This is certainly so, as we saw users perceive themselves to be part of different monolithic categories who act together, almost promoting a sense of community. And five respondents referred directly to getting a sense of what is important in a community, whether it is one of nationalists or television fans from other profiles. In this sense, there is the possibility both of fragmentation of specialist smaller groups, but also the collective streamlining of these, as users collectively come to know what the defining features of the group are.

(5) Do users mainly claim identities implicitly rather than explicitly? This would certainly appear to be the case. One user said that they were part of a cool surfer community. This would be signalled by stylised images, often taken off the Internet rather than being their own.

(6) Do users stress consumer identities over personally narrated ones? There was a lack of mention of personal narrative to signal identity. And consumer realised identities were prominent alongside those of nationalism. For example, the cool surfer mentioned having images of products and surf clothing on his profile, as did a person who mentioned bodybuilding.

So what can we say overall in response to Livingstone's (2008) broader question as to how people position themselves to engage with particular communities or kinds of other users on Facebook? It is clear that there is a sense of self-awareness of signalling membership of a number of groups who are assumed to be monolithic. These can be contradictory. A nationalist interested in biological purity can also signal him or herself as a fan of a particular kind of music. This will frequently be done on profiles through key images, but also through links to user groups, and it may be implicit. Often the aesthetics of the profile will be considered important to give a sense of signifying identity, while much of the imagining of coherent communities - where members will recognise and know each other even though 
they don't meet - may in some senses be like Anderson's (1991) imagined community through the press. Here the difference is that groups are multiple, shifting, and fragmented and members can move across them.

\section{Conclusion}

This research involved a study of Welsh students from one particular part of the country. In addition, it was a snapshot in terms of asking only simple questions. Further studies should compare parts of Wales with other places, such as perhaps English cities. But I would suggest that even this modest study can throw up some interesting points as to how we might think about Facebook and identity formation in the context of global communication. In the first place, however, what we should not lose sight of is what kinds of identity classifications are actually being used, and whose interests these serve. On the one hand, the reflexivity and bricolage of Facebook appears to point to a degree of freedom. On the other, it is extremely depoliticised. There is no sense of what people share with groups and communities, only what they are as individuals. This may be one reason we find so many students using biological definitions of national/ethic identity. And it is clear that this reflexivity, which has individualism and lifestyle at its heart, best serves the individualism of consumer capitalism. For example, you can show you are a good surfer by showing which products you use. In turn, advertisers are able to place products on user profiles. In this context, nationalism appears to play a new role as one of this assembly of identity classifications. On the one hand it appears less odious than former nationalisms used by governments to distract populations from political matters such as poverty and socialism, and to mobilise them for war. This new kind of national identity, sitting alongside being a fan of $\mathrm{Dr}$ Who, and being something that appears to be entirely individual, is not something you get the impression these students would die for. But such classifications do have consequences when we live in increasingly multicultural societies, and the fact that they appear as simply pleasant lifestyle categories may make them appear less discriminatory and exclusive. And this may be one question that we have to think about as regards social media like Facebook. To what extent does the easy reflexive performance of identity itself influence how different categories are understood and felt by the performers? Do they come to lose any sense of their consequences and relation to actual, real issues and persons in concrete, non-virtual communities?

So what of the possible potential of Facebook and other social media in the context of global communication? On the one hand new genres of communication can bring the possibilities of new forms of communicative activities and new forms of interaction. Facebook, and social media like it, are global phenomena and contain the potential for much wider forms of discursive sharing. Shi-xu (2005) seeks to consider the possibility for forming and disseminating discourses of wider social solidarity, and social media might be one important site for this. But from the evidence gathered in this paper the solidarities found are weak, shiftable and orbit around the individual. They appear to be little more than people exhibiting choices, over fashion, activities that are temporary and focused towards micro communities of interest. At least in this research no evidence was found that users were looking outwards to embrace or be challenged by difference, to places where new discourses might be experienced. While social media contain all the potential for global interactions they appear to foster more specialist interactions. And we 
must not make the mistake of assuming that new forms of media will automatically foster new kinds of identity patterns. Identity categories are not given in nature and nor are they created spontaneously. They are created in language, and we cannot describe ourselves outside of the categories available in any society at a given time. Facebook may simply be one site where we can assess those that are dominant in society at this given time.

\section{Note}

1. Friending on Facebook is the process of making and maintaining friendships. Users set-up personal profiles and make connections to other profiles on a reciprocal basis (Lewis and West 2009, 1209).

\section{Notes on contributor}

Dr Gwen Bouvier is a Lecturer of Communication, Media and Cultural Studies at the University of Glamorgan, Cardiff, UK. She earned a Ph.D. from Aberystwyth University in television news and journalism. She is currently teaching courses on international media, imagined communities and representation theory. Her publications have focused on 9/11 and representation, discourse analysis and social media.

\section{References}

Abousnnouga, G., and D. Machin. 2008. The visual institutionalisation of discourses in war monuments. In Language and power: An introduction to institutional discourse, ed. A. Mayr, 115-37. London: Continuum.

Ambady, N., and J. Skowronski, eds. 2008. First impressions. New York, NY: Guilford.

Anderson, B. 1991. Imagined communities: Reflections on the origin and spread of nationalism. London: Verso.

Ashcroft, B., Griffiths, G., and H. Teffin. 2007. Key concepts in post-colonial studies. London: Routledge.

Back, M., J. Stopfer, S. Vazire, S. Gaddis, S. Schmukle, B. Egloff, and S. Gosling. 2010. Facebook profiles reflect actual personality, not self-idealization. Psychological Science 21, no. 3: 372-4.

Bhabha, H. 1994. The location of culture. London: Routledge.

Billig, M. 2002. Banal nationalism. London: Sage.

Bohata, K. 2004. Postcolonialism revisited: Writing Wales in English. Cardiff: University of Wales Press.

Boyd, D., and J. Heer. 2006. Profiles as conversation: Networked identity performance on friendster. Proceedings of the Hawaii International Conference on System Sciences, Kauai, HI, USA.

Champagne, E. 2008. Girlfriend in a comma: Romancing on the internet. New Media \& Society 10, no. 1: 159-66.

Chaney, D. 1996. Lifestyles. London: Routledge.

Chaney, D. 2001. From ways of life to lifestyle: Rethinking culture as ideology and sensibility. In Culture in the communication age, ed. J. Lull, 75-88. London: Routledge.

Chaney, D. 2002. Cultural change and everyday life. Basingstoke: Palgrave.

Chiung-Wen, J., W. Ching-Chan, and T. Yi-Ting. 2011. The closer the relationship, the more the interaction on Facebook? Investigating the case of Taiwan users. Cyberpsychology, Behavior, and Social Networking 14, no. 7-8: 473-6.

Coupland, N. 2010. Welsh linguistic landscapes 'from above' and 'from below'. In Semiotic landscapes: Language, image, space, ed. A. Jaworski and C. Thurlow, 77-101. London: Continuum. 
Davis, E., C. Di Fede, K. Dobbins, L. Kamiya-Nada, and A. Van Seyfried. 2011. Privacy concerns, identity management, and awareness on Facebook. Meta-Communicate 1, no. 1: $1-17$.

DiMicco, J., and D. Millen. 2007. Identity management: Multiple presentations of self in Facebook. GROUP'07, November 4-7, 2007, Sanibel Island, Florida, FL, USA.

Durkheim, E. 1897/2002. Suicide. London: Routledge.

Facebook. 2011. Statistics. http://www.facebook.com/press/info.php?statistics (accessed October 20, 2011).

Featherstone, M. 1992. Cultural theory and cultural change. London: Sage.

Featherstone, M. 1995. Undoing culture: Globalization, postmodernism and identity. London: Sage.

Foucault, M. 1982. The subject and power. In Beyond structuralism and hermeneutics, ed. H. Dreyfus and P. Rabinov, 208-26. Brighton: Harvester.

Gellner, E. 2006. Nations and nationalism. Ithaca, NY: Cornell University Press.

Gergen, K. 1991. The saturated self: Dilemmas of identity in contemporary life. New York, NY: Basic Books.

Giddens, A. 1991. Modernity and self-identity: Self and society in the late modern age. Cambridge: Polity Press.

Goffman, E. 1959. The presentation of self in everyday life. Garden City, NY: Anchor Books.

Hall, S. 1989. Cultural identity and diaspora. In Community, culture, difference, ed. J. Rutherford, 222-37. London: Lawrence \& Wishart.

Hearn, A. 2008. Meat, mask, burden: Probing the contours of the branded 'self'. Journal of Consumer Culture 8, no. 2: 197-217.

Hobsbawm, E. 1997. On history. London: Weidenfeld \& Nicolson.

Honeycutt, C., and D. Cunliffe. 2010. The use of the Welsh language on Facebook. Information, Communication and Society 13, no. 2: 226-48.

Jenkins, G., and M. Williams, eds. 2000. Let's do our best for the ancient tongue: The Welsh language in the twentieth century. Cardiff: University of Wales Press.

Kress, G. 1982. Learning to write. London: Routledge \& Kegan Paul.

Lampe, C., N. Ellison, and C. Steinfield. 2006. A Face (book) in the crowd: Social searching vs. social browsing. Proceedings of CSCW'06, Banff, Canada, 167-70.

Lampe, C., N. Ellison, and C. Steinfield. 2007. A familiar Face(book): Profile elements as signals in an online social network. Proceedings of CHI 2007, San Jose, CA, USA.

Lewis, J., and A. West. 2009. 'Friending': London based undergraduates' experience of Facebook. New Media \& Society 11, no. 7: 1209-29.

Livingstone, S. 2008. Taking risky opportunities in youthful content creation: Teenagers' use of social networking sites for intimacy, privacy and self-expression. New Media \& Society 10: 393-411.

Machin, D., and T. Van Leeuwen. 2007. Global media discourse. London: Routledge.

Machin, D., and T. Van Leeuwen. 2008. Branding the self. In Identity trouble, ed. C.R. CaldasCoulthard and R. Iedema, 43-56. Basingstoke: Palgrave Macmillan.

Manago, A.M., M.B. Graham, P.M. Greenfield, and G. Salimkhan. 2008. Self-presentation and gender on MySpace. Journal of Applied Developmental Psychology 29: 446-58.

Mayr, A., and D. Machin. 2012. The language of crime and deviance. London: Continuum.

Negus, K., and P. Roman-Velazquez. 2000. Globalization and cultural identities. In Mass media and society, ed. J. Curran and M. Gurevitch, 329-45. London: Arnold.

Parks, M.R., and K. Floyd. 1996. Making friends in Cyberspace. Journal of ComputerMediated Communication 1, no. 4. http://jcmc.indiana.edu/voll/issue4/parks.html (accessed April 25, 2010).

Shi-xu. 2005. A cultural approach to discourse. Basingstoke: Palgrave Macmillan.

Simmel, G. 1917/1971. On individuality and social forms. Chicago, IL: University of Chicago Press.

Singh, E.G. 2001. Multiculturalism in contemporary Britain: Reflections on the 'Leicester model'. International Journal on Multicultural Societies 5, no. 1: 40-54.

Sunden, J. 2003. Material virtualities: Approaching online textual embodiment. New York, NY: Peter Lang Publishing.

Teo, P. 2000. Racism in the news: A critical discourse analysis of news reporting in two Australian newspapers. Discourse \& Society 11: 7-49. 
Tong, S., B. Van Der Heide, L. Langwell, and J.B. Walther. 2008. Too much of a good thing? The relationship between number of friends and interpersonal impressions on Facebook. Journal of Computer-Mediated Communication 13: 531-49.

Tönnies, F. 2001. Community and civil society. Cambridge: Cambridge University Press.

Van Leeuwen, T. 1996. The representation of social actors. In Texts and practices: Readings in critical discourse analysis, ed. C.R. Caldas-Coulthard and M. Coulthard, 32-70. London: Routledge.

Vazire, S., and S.D. Gosling. 2004. E-perceptions: Personality impressions based on personal websites. Journal of Personality and Social Psychology 87: 123-32.

Von Sturmer, J. 1981. Talking with aborigines. Australian Institute of Aboriginal Studies Newsletter 15: 13-30.

Walters, G. 1994. Drugs and crime in lifestyle perspective. London: Sage.

Wellman, B., J. Salaff, D. Dimitrova, L. Garton, M. Gulia, and C. Haythornthwaite. 1996. Computer networks as social networks: Collaborative work, telework, and virtual community. Annual Review of Sociology 22: 213-38.

Westlake, E.J. 2008. Friend me if you Facebook. Generation Y and performative surveillance. The Drama Review 52, no. 4: 21-40.

Williams, C.H., and A.D. Smith. 1983. The national construction of social space. Progress in Human Geography 7: 502-18.

Zablocki, B., and M. Kanter. 1976. The differentiation of lifestyles. Annual Review of Sociology 2: 269-98.

Zhao, S., S. Grasmuck, and J. Martin. 2008. Identity construction on Facebook: Digital empowerment in anchored relationships. Computers in Human Behavior 24: 1816-36. 